\title{
Keanekaragaman Mikroalga Bacillariophyta Di Sungai Mesat Kota Lubuklinggau
}

\author{
Sepriyaningsih $^{1)} \&$ Harmoko $^{2)}$ \\ ${ }^{1}$ Pendidikan Biologi, Jurusan Pendidikan MIPA, STKIP PGRI Lubuklinggau. \\ email: sepriyaningsih26@gmail.com \\ ${ }^{2}$ Pendidikan Biologi, Jurusan Pendidikan MIPA, STKIP PGRI Lubuklinggau. \\ email: putroharmoko@gmail.com
}
APA Citation: Sepriyaningsih \& Harmoko. (2020). Keanekaragaman Mikroalga Bacillariophyta Di Sungai Mesat Kota Lubuklinggau. Quagga: Jurnal Pendidikan dan Biologi, 12(2), 156-162. doi: 10.25134/quagga.v12i2.2768.

Received: 27-04-2020

Accepted: 04-06-2020

Published: 01-07-2020

\begin{abstract}
Abstrak: Penelitian ini bertujuan untuk memberikan informasi tentang keanekaragaman mikroalga chloropyta di sungai Mesat Kota Lubuklinggau. Jenis penelitian adalah penelitian survey sehingga pengumpulan data dalam penelitian ini dilakukan secara observasi. Penelitian ini dilakukan pada bulan Februari- April 2020. Penelitian dilakukan di Sungai Mesat, sampel mikroalga diambil dari 3 stasiun yang berbeda mengikuti aliran sungai. Berdasarkan hasil penelitian yang dilakukan, jenis mikroalga bacilliriophyta yang ditemukan di Sungai Mesat Kota Lubuklinggau, terdiri dari: 3 Kelas, 9 Ordo, 9 Famili, 10 Genus, 16 Spesies. Berdasarkan hasil analisis Nilai keanekaragaman di stasiun 1 sebesar 1.14, stasiun 2 sebesar 1.51, dan stasiun 3 sebesar 1.23. Sedangkan untuk nilai dominansi di stasiun 1 sebesar 0.01, stasiun 2 sebesar 0.022, dan stasiun 3 sebesar 0.014. Untuk nilai keseragaman di stasiun 1 sebesar 0.39, stasiun 2 sebesar 0.52, dan stasiun 3 sebesar 0.42. Pengukuran faktor abiotik di sungai Mesat terdiri dari: suhu, oksigen terlarut, keasaman dan kecerahan. Suhu di stasiun 1 sebesar $27.2^{\circ} \mathrm{C}$, stasiun 2 sebesar $26.56{ }^{\circ} \mathrm{C}$ dan stasiun 3 sebesar $26.87^{\circ} \mathrm{C}$. Untuk kandungan oksigen terlarut di stasiun 1 sebesar $45.94 \mathrm{mg} / \mathrm{L}$, stasiun 2 sebesar $42.31 \mathrm{mg} / \mathrm{L}$, dan stasiun 3 sebesar $44.63 \mathrm{mg} / \mathrm{L}$. sedangkan keasaman di stasiun 1 sebesar 6.70, stasiun 2 sebesar 6.63 dan stasiun 3 sebesar 6.6. Kemudian Kecerahan sungai Mesat pada stasiun 1 sebesar $16.33 \mathrm{~cm}$, stasiun 2 sebesar $22 \mathrm{~cm}$ dan stasiun 3 sebesar $18.63 \mathrm{~cm}$. Keanekaragaman mikroalga divisi Chlorophyta di Sungai Mesat Kota Lubuklinggau dalam Kategori Sedang.
\end{abstract}

Katakunci : Mikroalga, Bacilliriophyta, sungai Mesat

\begin{abstract}
This study aims to provide information about the diversity of chloropyta microalgae in the Mesat river, Lubuklinggau City. This type of research is a survey research so that the data collection in this study was conducted by observation. This research was conducted in February-April 2020. Research was conducted in the Mesat River, microalgae samples were taken from 3 different stations following the river flow. Based on the results of research conducted, the type of bacilliriophyta microalgae found in the Mesat River, Lubuklinggau City, consists of: 3 Classes, 9 Orders, 9 Families, 10 Genera, 16 Species. Based on the analysis of diversity value at station 1 is 1.14, station 2 is 1.51 , and station 3 is 1.23. Whereas the dominance value at station 1 is 0.01 , station 2 is 0.022, and station 3 is 0.014 . For uniformity value at station 1 is 0.39 , station 2 is 0.52 , and station 3 is 0.42 . Measurement of abiotic factors in the Mesat river consists of: temperature, dissolved oxygen, acidity and brightness. The temperature at station 1 is 27.20C, station 2 is $26.560 \mathrm{C}$ and station 3 is 26.870C. For dissolved oxygen content at station 1 of $45.94 \mathrm{mg} / \mathrm{L}$, station 2 of $42.31 \mathrm{mg} / \mathrm{L}$, and station 3 of $44.63 \mathrm{mg} / \mathrm{L}$. while the acidity at station 1 is 6.70, station 2 is 6.63 and station 3 is 6.6. Then Mesat River Brightness at Station 1 is $16.33 \mathrm{~cm}$, Station 2 is $22 \mathrm{~cm}$ and Station 3 is $18.63 \mathrm{~cm}$. Chlorophyta division microalgae diversity in the Mesat River Lubuklinggau City in the Medium Category.
\end{abstract}

Keywords: Microalgae, Bacilliriophyta, Mesat river

\section{PENDAHULUAN}

Sungai merupakan daerah yang dilalui badan air yang bergerak dari tempat yang tinggi ke tempat yang lebih rendah dan melalui permukaan atau bawah tanah. Karena itu, dikenal dengan istilah sungai dan sungai bawah tanah (Kordi, 2008). Kota Lubuklinggau, sebagai salah satu kota madya di provinsi Sumatera Selatan juga memiliki beberapa sungai. Sungai di kota Lubuklinggau terdiri dari Sungai Kelingi, Sungai Mesat, Sungai Malus, Sungai Kasie dan Sungai Kati (Perda Kota Lubuklinggau No 1 tahun 2012). Salah satu sungai terbesar yang ada dan menjadi icon kota Lubuklinggau adalah sungai Mesat.

Sungai Mesat merupakan aliran sungai yang melintasi Kota Lubuklinggau dan sebagian berada di permukiman penduduk perkotaan 
yaitu Kota Lubuklinggau. Aliran Sungai Mesat mengalir dari daerah Rumah Sakit Sobirin di Kota Lubuklinggau sampai bermuara ke sungai Beliti. Penelitian ini hanya akan mengambil pada batasan aliran Sungai Mesat yang berada di Kota Lubuklinggau saja, khususnya di Kecamatan Lubuklinggau Timur II. (Pemerintah Kecamatan Lubuklinggau Timur II Kota Lubuklinggau). Keadaan Sungai Mesat yang ditemukan peneliti saat melakukan observasi yaitu, keadaan perairan yang banyak sampah pembuangan dari warga hulu sungai, keadaan sekitar yang terbengkalai terlihat tidak terurus, dan banyak tumbuhan liar di sekitar Sungai Mesat. Keadaan tersebut sangat memprihatinkan, sehingga perlunya kesadaran dari semua pihak yang bersangkutan untuk perubahan Sungai Mesat ke arah yang lebih baik.

Salah satu cara untuk melihat tingkat pencemaran perairan di sungai yaitu daat dilakukan secara biologi menggunakan indikator mikroalga. Mikroalga adalah tanaman yang paling efisien dalam menangkap dan memanfaatkan energi matahari dan $\mathrm{CO}_{2}$ untuk keperluan fotosintesis. Meskipun berfotosintesis mikroalga berbeda dari tanaman karena mikroalga tidak memiliki jaringan tanaman (Nurhayati, 2013). Mikroalga bermnafaat sebagai indikator kesuburan ekosistem perairan (Winahyu, 2013).

Beberapa mikroalga yang sudah digunakan sebagai bioindikator pencemaran perairan yaitu: Mikroalga epilitik (Purba, 2015 dan Giasi, 2015), Mikroalga perifitik (Andriansyah, 2014), Cyanobacteria (Prihantini, 2008). Salah satunya yaitu dari divisi Bacillariophyta: Synedra sp (Isti'anah, 2015), dan Diatom (Astuti, 2012). Tujuan penelitian ini yaitu untuk mengetahui jenis-jenis mikroalga divisi Bacillariophyta yang ada di Sungai Mesat Kota Lubuklinggau.

\section{METODOLOGI PENELITIAN Jenis Penelitian}

Jenis penelitian adalah penelitian survey sehingga pengumpulan data dalam penelitian ini dilakukan secara observasi. Penelitian ini dilakukan pada bulan Februari- April 2020. Penelitian dilakukan di Sungai Mesat, sampel mikroalga diambil dari 3 stasiun yang berbeda mengikuti aliran sungai. Penentuan stasiun berpacu pada hasil penelitian Andriansyah (2014), yaitu berdasarkan perbedaan ekosistem yang ada di lingkungan tersebut, stasiun I berada pada ekosistem dekat perumahan masyarakat (Kelurahan Mesat Jaya), stasiun II berada pada ekosistem dekat perkolaman (Kelurahan Mesat Seni), dan stasiun III berada pada ekosistem dekat perkebunan dan perkolaman (Kelurahan Mesat Seni) di Kecamatan Lubuklinggau Timur II Kota Lubuklinggau. Pengambilan sampel dilakukan sebanyak tiga kali ulangan. Sampel kemudian di identifikasi di laboratorium dan dilihat keanekaragamannya.

\section{Alat dan Bahan}

Alat yang digunakan dalam penelitian ini adalah sebagai berikut: plankton net, mikroskop, gelas objek, gelas penutup, botol, pipet tetes, gelas kimia, kamera, label, pena, buku, kapas, pH meter, secchi disk, DO meter, dan termometer.Bahan yang digunakan dalam penelitian ini adalah sebagai berikut: sampel air, alkohol 70\% dan etanol.

\section{Prosedur Penelitian}

Prosedur penelitian yang digunakan dalam penelitian ini meliputi: a) Pengambilan sampel dilakukan di stasiun yang telah ditetapkan dengan waktu antara pukul 08.00-10.00 WIB. Satu stasiun terdiri dari 3 titik, yaitu bagian tepi kanan, tepi kiri dan tengah sungai. b) Setelah menentukan stasiun dan titik pengambilan sampel, selanjutnya melakukan pengukuran faktor abiotik yang terdiri dari: suhu, keasaman, oksigen terlarut, dan kecerahan air. Hasil pengukuran faktor abiotik kemudian di catat dan direkapitulasi dalam sebuah tabel. c) Selanjutnya, yaitu melakukan pengambilan sampel air dengan menggunakan plankton net, dengan cara menyaring air sungai. Air yang tertampung kemudian dipindahkan ke dalam botol dan diberikan alkohol 4 tetes. Botol sampel cara penyaringan dengan menggunakan plankton net dan disimpan dalam botol, kemudian diberi label, kode stasiun, titik dan tanggal pengambilan. d) Prosedur a dan $b$ di atas diulang untuk stasiun 2, 3 dan 4, kemudian pengambilan sampel diulang sebanyak 3 kali pengulangan. e) Sampel air sungai dibawa ke laboratorium Biologi STKIP-PGRI Lubuklinggau untuk diamati. f) Sampel air diletakkan dalam cawan petri, kemudian diambil satu tetes dan diletakkan di objek glass dan ditutup untuk dilakukan pengamatan dengan menggunakan mikroskop. g) Mikroalga Bacilliriophyta yang didapat kemudian difoto untuk selanjutnya di identifikasi dan dianalisis. 


\section{Teknik Analisis Data}

Mikroalga yang didapatkan dikumpulkan dan diindentifikasi dalam bentuk tabel nantinya, begitu juga faktor abiotiknya.Identifikasi spesies mikroalga Chlorophyta menggunakan buku (Belcher dan Swale, 1978), (Fogg et al. 1973), (Botes, 2001), (Vuuren et al. 2006), (Wehr dan Sheath, 2003), dan (Bellinger dan Sigee, 2010). Jenis mikroalga Bacilliriophyta yang diperoleh kemudian di analisis, yang terdiri:

a. Keanekaragaman menggunakan rumus Shanon-Wiener:

$$
\mathrm{H}=\sum_{i=1}^{s} p i \ln p i
$$

Dengan $p i \frac{n i}{N}$

Keterangan:

$\mathrm{H}=$ indeks keragaman

$\mathrm{ni}=$ jumlah spesies $\mathrm{i}$

$\mathrm{N}=$ jumlah total spesies

$\mathrm{S}=$ jumlah spesies dalam sampel

b. Dominansi:

$$
\mathrm{C}=\sum_{i=1}^{S}(\mathrm{Pi})^{2}
$$

Keterangan:

$\mathrm{C}=$ indeks dominansi

$\mathrm{Pi}=$ perbandingan proporsi spesies ke $\mathrm{i}$

$\mathrm{S}=$ Jumlah spesies yang ditemukan

c. Keseragaman:

$$
E=\frac{H^{\prime}}{H m a k s}
$$

Keterangan

$\mathrm{E}=$ Indeks Keseragaman

$\mathrm{H}^{\prime}=$ Indeks keanekaragaman jenis

$\mathrm{H}$ maks $=\ln \mathrm{s}$ dan $\mathrm{s}$ merupakan jumlah spesies yang ditemukan.

\section{HASIL DAN PEMBAHASAN}

Berdasarkan hasil penelitian yang dilakukan, jenis mikroalga bacilliriophyta yang ditemukan di Sungai Kelingi Kota Lubuklinggau, terdiri dari: 3 Kelas, 9 Ordo, 9 Famili, 10 Genus, 16 Spesies. Mikroalga divisi Bacilliriophyta yang ditemukan di Sungai Mesat Kota Lubuklinggau terdiri dari Cymbella Sp, Eunotia Sp, Fragilaria crotonensis, Fragillaria capucina, Fragillaria tenera, Navicula gracilis, Navicula radiosa, Nitzschia $\mathrm{Sp}$, Surirella elegans, Surirella minuta, Surirella tenera,
Synedra acus, Synedra ulna, Melosira varians, Cyclotella $\mathrm{Sp}$, dan Tabellaria flocculosa. Mikroalga Bacilliriophyta yang didapat, kemudian dilakukan analisis untuk melihat keanekaragaman, dominansi dan keseragamannya. Secara detail, hasil analisis dapat dilihat pada Tabel 1 berikut ini:

Tabel 1. Hasil Analisis Keanekaragaman, Dominansi dan Keseragaman Mikroalga Divisi Bacillariophyta di Sungai Mesat Kota Lubuklinggau

\begin{tabular}{llrrr}
\hline \multicolumn{4}{c}{ No. } & \multicolumn{2}{c}{ Nilai } & \multicolumn{3}{c}{ Stasiun } \\
\cline { 3 - 5 } & & $\mathbf{1}$ & $\mathbf{3}$ \\
\hline 1 & Keanekaragaman & 1,14 & 1,51 & 1,23 \\
2 & Dominansi & 0,01 & 0,022 & 0,014 \\
3 & Keseragaman & 0,39 & 0,52 & 0,42 \\
\hline
\end{tabular}

Berdasarkan Tabel 1, keanekaragam tertinggi berada di stasiun 2 dengan nilai 1,51 dan terendah berada di staisun 1 dengan nilai 1,14. Berdasarkan analisis keanekaragaman Shanon Wiener, memperlihatkan bahwa keanekaragaman mikroalga divisi Bacilliriophyta tertinggi berada di stasiun 2 dengan nilai 1,51 yang memiliki kriteria keanekaragaman "sedang". Keanekaragam terendah berada di stasiun 1 dengan nilai 1,14 yang memiliki kriteria keanekaragaman "sedang, kriteria tersebut berdasarkan (Winahyu et al. 2013).

Keanekaragaman jenis di suatu perairan dapat memberikan informasi tentang tingkat pencemaran suatu perairan (Wibowo et al. 2009). Indeks keanekaragaman (H') merupakan suatu angka yang tidak memiliki satuan dengan kisaran 0-3. Tingkat keanekaragaman akan tinggi jika nilai $\mathrm{H}^{\prime}$ mendekati 3, sehingga hal ini menunjukkan kondisi perairan baik. Sebaliknya jika nilai H' mendekati 0 maka keanekaragaman rendah dan kondisi perairan kurang baik (Odum, 1998). Nilai dominansi tertinggi berada di stasiun 2 dengan nilai 0,022 dan terendah berada di staisun 1 dengan nilai 0,01 . Nilai dominansi digunakan untuk melihat spesies yang sering ditemukan dalam suatu habitat tertentu. Berdasarkan analisis, dominansi mikroalga divisi Bacilliriophyta tertinggi berada di stasiun 2 dan terendah di stasiun 1, nilai tersebut dalam kriteria dominansi rendah $0<\mathrm{C} \leq 0,5$ (Krebs, 1989). Indeks dominansi menggambarkan ada tidaknya spesies yang mendominasi spesies yang lain (Yuliana et al. 2012). Hasil 
perhitungan dominansi di 3 stasiun banyak nilai yang mendekati 0 (nol) dibandingkan yang mendekati 1 (satu). Berdasarkan hal tersebut, dapat dijelaskan bahwa secara umum di Sungai Mesat selama penelitian tidak terjadi dominansi mikroalga khususnya divisi Bacilliriophyta.

Sedangkan nilai keseragaman tertinggi berada di stasiun 2 dengan nilai 0,52 dan nilai keseragaman terendah berada di stasiun 1 dengan nilai 0,39 . Tingkat keseragaman spesies merupakan gambaran sebaran individu dalam komunitas (Yudasmara, 2015). Berdasarkan perhitungan dengan nilai keseragaman tersebut termasuk dalam kriteria "keseragaman jenis tinggi" (Krebs, 1985). Hal ini dikarenakan Sungai Mesat memiliki panjang dan lebar yang sangat luas, sehingga mikroalga Bacilliriophyta dapat hidup leluasa sesuai dengan habitatnya.

Genus Cyclotella merupakan diatom planktonik yang umum ditemukan di seluruh dunia dan tersebar luas di lingkungan danau, sungai, laut dan air payau (Vuuren, 2006). Cylotella merupakan jenis diatom yang berbentuk cakram kecil. Bagian tengah berbentuk rata. Di sekitar tepi terdapat pita lebar. Sel Cyclotella berbentuk segi empat. Setiap sel mengandung banyak kloroplas berbentuk diskoid, sel berdiameter antara 5-30 $\mu \mathrm{m}$. Saat penelitian hanya didapatkan satu spesies yaitu Cylotella sp.

Genus Eunotia, sering ditemukan pada air yang asam, misalnya: danau dan rawa-rawa. Genus ini juga dapat menjadi bagian penting dari peripiton sungai, terutama sebagai filamen di sungai dataran rendah yang relatif bersih (Biggs, 2000).Saat penelitian didapatkan hanya 1 spesies yaitu Eunotia sp.

Genus Fragilaria sering berlimpah di pada waduk yang sedang mengalami eutrofikikasi. Fragilaria dapat merespon secara cepat terhadap fosfor yang meningkat. Fragilaria dapat ditemukan di seluruh dunia (Wehr \& Sheath, 2003).Saat penelitian hanya didapatkan 3 spesies yaitu Fragilaria crotonensis, Fragalaria capucina, dan Flagalaria tenera.

Genus Synedra, termasuk golongan diatom yang berbentuk panjang. Bergerak dengan bebas sebagai planktonik dan melekat pada substrat dengan lendir. Panjang sel mencapai $500 \mu \mathrm{m}$. Berkoloni tapi juga dapat sebagai sel tunggal atau sebagai epifit yang menempel. Hidup di air tawar (Bellinger, 2010). Synedra juga diketahui memiliki kemampuan bertahan terhadap perubahan kondisi lingkungan yangtidak menguntungkan, memiliki sel pembungkus yang berlapis (Conradie, 2008). Selain itu juga mampu bertahan dalam lingkungan yang rendah nutrisi (oligotrifik) dengan konsentrasi nitrogen dan phospat rendah. Hal ini dikarenakan Synedra mampu mengakumulasi nutrisi dan menyimpannya sebagai cadangan makanan dalam bentuk polimer yang tidak terlarut (Venter, 2003). Saat penelitian hanya didapatkan 2 spesies yaitu Synedra acus dan Synedra ulna.

Genus Nitzschia mimiliki banyak spesies, panjangnya 5-100 $\mu \mathrm{m}$, paling mudah dibedakan dalam keadaan hidup dari Navicula dan sekutunya oleh dua kloroplas di ujung sel, bukan di sisi. Ada juga spesies sigmoid besar, panjangnya sampai $600 \mu \mathrm{m}$, tapi tidak seperti Gyrosigma, ia memiliki sisi parallci dan ujungnya tumpul (Belcher, 1978).Saat penelitian didapatkan hanya 1 spesies yaitu Nitzschia sp.

Genus Surirella memiliki katup besar, elips atau oval, berbentuk persegi panjang atau panjang sampai dengan 15-200 $\mu \mathrm{m}$, tepi katup sering membentuk sayap, hidup di kolam, danau dan sungai (Belcher, 1978). Sisi lebih kecil (atau sedikit bulat), ujung kerucut. Ukuran panjang 20-30 $\mu \mathrm{m}$ dan lebar sekitar $10 \mu \mathrm{m}$ (Bellinger, 2010). Saat penelitian didapatkan 3 spesies yaitu Surirella tenera, Surirella minuta, dan Surirella elegans.

Divisi Bacillariophyta ini disebut juga sebagai diatom. Divisi Bacillariophyta terdiri dari diatom-diatom yang hidup di air tawar, air laut dan didalam tanah yang lembab, bersifat unisesuler, berkoloni, dan setiap sel mengadung satu nukleus (Pratiwi, 2008). Peran diatom sebagai produsen dalam rantai makanan yakni penghasil bahan organik dan oksigen (Winahyu.et.al, 2013).

Divisi Bacillariophyta memiliki kemampuan beradaptasi terhadap arus yang kuat sampai lambat karena memiliki alat penempel pada substrat berupa tangkai bergelatin (Andriansyah.et.al, 2014). Saat penelitian berlangsung lokasi penelitian tidak memiliki arus yang deras seperti sungai, mikroalga yang ditemukan diduga menempel di tumbuhantumbuhan yang ada di danau. Hal yang sama juga diungkapkan oleh Basmi (1999) sebagian besar anggota kelas Bacillariophyceae memiliki sitoplasma yang didalamnya mengandung 
mukopolisakarida yang mampu mengeluarkan cairan perekat untuk menempel pada substrat.

Tabel 2. Pengukuran Faktor Abiotik Di Sungai Mesat Kota Lubuklinggau

\begin{tabular}{ccrrrr}
\hline \multirow{2}{*}{ No } & Parameter & \multicolumn{3}{c}{ Stasiun } & \multirow{2}{*}{ Rata2 } \\
\cline { 3 - 5 } & & \multicolumn{1}{c}{$\mathbf{2}$} & $\mathbf{3}$ & \\
\hline 1 & Suhu $\left({ }^{\circ} \mathrm{C}\right)$ & 27,20 & 26,56 & 26,87 & 26,87 \\
2 & Oksigen Terlarut (mg/L) & 45,94 & 42,31 & 45,63 & 44,63 \\
3 & Keasaman & 6,70 & 6,63 & 6,60 & 6,65 \\
4 & Kecerahan $(\mathrm{cm})$ & 16,33 & 22,00 & 17,56 & 18,63 \\
\hline
\end{tabular}

Berdasarkan Tabel 2, suhu rata-rata di sungai Mesat Kota Lubuklinggau yaitu sebesar $26,87^{\circ} \mathrm{C}$, oksigen terlarut dengan rata-rata 44,63 $\mathrm{mg} / \mathrm{L}$, keasaman dengan rata-rata 6,65 dan kecerahan dengan rata-rata sebesar 18,63 cm. Faktor abiotik di Sungai Mesat yang diukur antara lain: suhu, keasaman, kecerahan dan oksigen terlarut. Suhu merupakan salah satu faktor lingkungan yang penting bagi makhluk hidup (Harmoko dan Krisnawati, 2018). Suhu tertinggi berada di stasiun 1 yaitu $27,20^{\circ} \mathrm{C}$ dan suhu terendah berada di stasiun 2 dengan nilai $26,56^{\circ} \mathrm{C}$, dengan suhu rata-rata di Sungai Mesat sebesar $26,87^{\circ} \mathrm{C}$. Rentang suhu tersebut adalah suhu yang ideal untuk pertumbuhan mikroalga, batas suhu optimum pertumbuhan mikroalga adalah sekitar $20-30^{\circ} \mathrm{C}$ (Maresi et al. 2015), 26$28^{0} \mathrm{C}$ (Yudasmara, 2015). Suhu air untuk pertumbuhan biota perairan yaitu berkisar diantara 28-32 ${ }^{0}$ C (Saputra, 2016). Suhu optimum pertumbuhan fitoplankton adalah $20^{\circ} \mathrm{C}-30^{\circ} \mathrm{C}$ (Effendi, 2003). Tinggi rendahnya suhu suatu badan perairan sangat mempengaruhi kehidupan organisme air, termasuk mikroalga (Yudasmara, 2015).

Faktor abiotik yang diukur selanjutnya yaitu oksigen terlarut. Kadar oksigen terlarut tertinggi di Sungai Mesat berada di stasiun 1 dengan nilai $45,94 \mathrm{mg} / \mathrm{L}$ dan terendah berada di stasiun 2 dengan nilai $42,31 \mathrm{mg} / \mathrm{L}$ sedangkan nilai rata-rata oksigen terlarut yaitu sebesar 44,63 mg/L. Oksigen dibutuhkan oleh semua jasad hidup untuk respirasi, metabolisme atau pertukaran zat yang kemudian menghasilkan energi untuk pertumbuhan dan reproduksi (Sulaiman, 2012); (Simanjutak, 2007).

Sedangkan Oksigen terlarut adalah jumlah oksigen (mg O2) yang dibutuhkan untuk mengoksidasi zat organik yang terlarut dalam 1 liter air (Hayati, 2016). Oksigen terlarut dalam laut dimanfaatkan oleh organisme perairan untuk respirasi dan penguraian zat-zat organik oleh mikro-organisme. Menurunnya kadar oksigen terlarut di perairan menyebabkan terganggunya ekosistem perairan dan mengakibatkan semakin berkurangnya populasi biota (Patty et al. 2015). Saat pengukuran kadar oksigen terlarut di Sungai Mesat sebesar 44,63 $\mathrm{mg} / \mathrm{L}$. Jika disesuaikan degan tabel kriteria oksigen terlarut dari Lee et al. (1978) nilai tersebut memiliki kriteria "tidak tercemar". Hal ini terlihat dari kondisi Sungai Mesat yang masih bersih, namun saat musim hujan banyak sampah dan keruh. Kandungan oksigen terlarut (DO) minimum adalah 2 ppm dalam keadaan normal dan tidak tercemar oleh senyawa beracun (toksik) (Salmin, 2005).

Faktor abiotik selanjutnya yang diukur yaitu nilai keasaman. Nilai keasaman tertinggi di Sungai Kelingi berada di stasiun 1 dengan nilai 6,70 , nilai terendah berada pada stasiun 3 dengan nilai 6,60 dan nilai rata-rata keasaman yaitu 6,65. Derajat keasaman adalah nilai yang menunjukan aktivitas ion hidrogen dalam air. Nilai keasamaan suatu perairan dapat menunjukkan keseimbangan antara asam dan basa di suatu perairan tersebut (Winahyu et al. 2013). Organisme memiliki batas toleransi yang berbeda terhadap keasaman, kebanyakan perairan alami memiliki keasaman berkisar antara 6-9 (Saputra, 2016). Berdasarkan hal tersebut, kondisi Sungai Mesat memiliki keasaman yang stabil, sehingga mikroalga dapat tumbuh.

Faktor abiotik yang diukur selanjutnya yaitu, kecerahan. Nilai kecerahan tertinggi berada di stasiun 2 dengan nilai $22 \mathrm{~cm}$, kecerahan terendah di stasiun 1 dengan nilai $16,33 \mathrm{~cm}$, sedangkan rata-rata kecerahan di Sungai Mesat yaitu $18,63 \mathrm{~cm}$. Kecerahan dengan nilai $18,63 \mathrm{~cm}$ termasuk dalam kategori "keruh". Hal ini sesuai dengan pendapat 
(Arthington et al. 2006) yakni perairan keruh apabila nilai kecerahannya $0,25-1 \mathrm{~m}$. Kecerahan merupakan suatu ukuran biasan cahaya dalam air disebabkan adanya partikel koloid dan suspensi dari bahan organik (Saputra, 2016). Semua plankton menjadi berbahaya, apabila kecerahan sudah kurang dari $25 \mathrm{~cm}$. Kekeruhan yang tinggi menghambat penetrasi cahaya matahari dalam proses fotosintesis fitoplankton serta dapat menyebabkan pendangkalan. Penetrasi cahaya masuk kedalam air dipengaruhi oleh intensitas dan sudut datang cahaya, kondisi permukaan air, dan bahan yang terlarut serta tersuspensi di dalam air (Effendi, 2003).

\section{SIMPULAN}

Berdasarkan pembahasan di atas, maka simpulan dalam artikel ini adalah sebagai berikut: Mikroalga divisi Chlorophyta yang ditemukan di Sungai Mesat Kota Lubuklinggau terdiri dari Draparnaldia Sp, Stigeoclonium lubricum, Chlamydomonas Sp, Chlorococum Sp, Eudorina Sp, Volvox Sp, Pediastrum duplek, Pediastrum Simplek, Tetraedron Sp, Coelastrum Sp, Scenedesmus armatus, Scenedesmus dimorphus, Scenedesmus quadricauda, Ankistrodesmus Sp, Chlorella pyrenoidosa, Chlorella vulgaris, Oocystis $\mathrm{Sp}$, Rhizoclonium Sp, dan Ulothrix Sp. Keanekaragaman mikroalga divisi Bacilliriophyta di Sungai Mesat Kota Lubuklinggau dalam Kategori Sedang.

\section{UCAPAN TERIMA KASIH}

Kami mengucapkan terimakasih kepada Kementeri Riset dan Teknologi Republik Indonesia yang telah memberikan dana penelitian ini melalui skema Penelitian Dosen Pemula (PDP) Tahun 2020.

\section{REFERENSI}

Andriansyah., Tri, R.S, dan Irwan, L. 2014. Kualitas Perairan Kanal Sungai Jawi dan Sungai Raya Dalam Kota Pontianak Ditinjau dari Struktur Komunitas Mikroalga Perifitik. Jurnal Protobiont, 3(1): 61-70.

Arthington AH, Bunn SE, Poff NL, dan Naiman RJ. 2006. The challenge of providing environmental flow rules to sustain river ecosystems. Ecol Appl, 16(13): 11-18.

Astuti, R.P., Philip, T.I, \& Gede, S.S. 2012. Kelimpahan Beberapa Jenis Mikroalga
Diatom di Perairan Pulau GumilamoMagaliho, Halmahera Utara. Jurnal Ilmu dan Teknologi Kelautan Tropis, 4(1): 97106.

Basmi, J. 1999. Planktonologi: Plankton Sebagai Bioindikator Kualitas Perairan. Bogor: IPB.

Belcher H dan Swale E. 1978. A beginner's guide to freshwater algae. London: Her Majesty's Stationery Office.

Bellinger EG dan Sigee DC. 2010. Freshwater algae identification and use as bioindicators. London: Wiey Blcakwell.

Botes L. 2001. Phytoplankton identification catalogue. South Africa: Glaballast Monograph.

Conradie, K.R.S., Du Plessis \& A. Venter. 2008. School of Environmental Sciences ans Development: Botany South Africa. South African Journal of Botany 74:101110.

Effendi H. 2003. Telaah kualitas air bagi pengelolaan sumber daya dan lingkungan perairan. Yogyakarta: Kanisius.

Fogg GE, Stewart WDP, Fay P, dan Walsby AE. 1973. The blue-green algae. London: Academic Press.

Giasi, C., Ramli, U dan Abubakar, S.K. 2015. Identifikasi Mikroalga Epilitik sebagai Biomonitoring Lingkungan Perairan Sungai Bone. Skripsi. Gorontalo: Universitas Gorontalo.

Harmoko H dan Krisnawati Y. 2018. Keanekaragaman mikroalga divisi cyanobacteria di danau aur Kabupaten Musi Rawas. Jurnal Biodjati, 3(1): 8-14.

Hayati M. 2016. Perbandingan kadar oksigen terlarut antara air pdam dengan air sumur. The Journal of Muhammadiyah Medical Laboratory Technologist, 2(2): 8-15.

Isti'anah, D., Moch, F.H, dan Ainun, N.L. 2015. Synedra sp sebagai Mikroalga yang Ditemukan di Sungai Besuki Porong Sidoarjo, Jawa Timur. Jurnal Bioedukasi, 8(1): 57-59.

Kordi MGH. 2008. Budi daya perairan. Bandung: PT Citra Aditya Bakti.

Krebs C. 1989. Ecological methodology. New York: Harper Collins Publisher.

Maresi SRP, Priyanti, dan Yunita E. 2015. Fitoplankton sebagai bioindikator saprobitas perairan di situ bulakan Kota 
Tangerang. Al-Kauniyah Jurnal Biologi, $8(2), 113-122$.

Nurhayati T, Mochamad BH, dan Musthofa L. 2013. Penggunaan fotobioreaktor system batch tersirkulasi terhadap tingkat pertumbuhan mikroalga Chlorella vulgaris, Chlorella sp. dan Nannochloropsis oculata. Jurnal Keteknikan Pertanian Tropis dan Biosistem, 1(3): 249-257.

Odum EP. 1998. Dasar-dasar ekologi: terjemahan dari fundamentals of ecology. Alih bahasa Samingan, T. Edisi Ketiga. Yogyakarta: UGM Press.

Patty SI, Arfah H dan Abdul MS. 2015. Nutriens (phosphate, nitrate), dissolved oxygen, and dissolved $\mathrm{ph}$ and they relation to productivity of jikumerasa waters, Buru Island. Jurnal Pesisir dan Laut Tropis, 1 (1): 43-50.

Pratiwi, S.T. 2008. Mikrobiologi Farmasi.Yogyakarta: Erlangga.

Prihantini, N.B., Wisnu, W., Dian, H., Arya, W., Yuni, A \& Ronny R. 2008. Biodiversitas Cyanobacteria dari Beberapa Situ/Danau di Kawasan Jakarta-Depok-Bogor, Indonesia. Jurnal Makara Sains, 12(1): 44-54.

Purba, I.Y.S., Izmiarti \& Solfiyeni. 2015. Komunitas Algae Epilitik Sebagai Indikator Biologis di Sungai Batang Ombilin, Sumatera Barat. Jurnal Biologi Universitas Andalas (J. Bio. UA.), 4(2):138-144.

Salmin. 2005. Oksigen terlarut (DO) dan kebutuhan oksigen biologi (BOD) sebagai salah satu indikator untuk menentukan kualitas perairan. Oseana, 30(3), 21-26.

Saputra R. 2016. Keanekaragaman jenis plankton di danau Tahai Kelurahan Tumbang Tahai Kecamatan Bukit Batu Provinsi Kalimantan Tengah. Skripsi. Online at http://digilib.iainpalangkaraya.ac.id [diakses 1 Juli 2018].

Simanjutak M. 2007. Oksigen terlarut dan apparent oxygen utilization di Perairan Teluk Klabat Pulau Bangka. Ilmu Kelautan, 12 (2): 59-66.

Sulaiman TG. 2012. Struktur komunitas bacillariophyta (diatom) di area pertambakan marunda cilincing, Jakarta Utara. Skripsi. Online at http://http://lib.ui.ac.id [diakses 1 Juli 2018].

Venter, A., A Jordaan \& A.J.H Pieterse. 2003. Oscillatoria Simplicissima: A Taxonomical Study. School of Environmental Sciences and Development: Botany. South Africa. Journal Water SA 29 (1): 101-104.

Vuuren SJV, Jonathan T, Carin VG, dan Annelise G. 2006. Easy identification of the most common freshwater algae. South African: North-West University noorowes-universitiet.

Wehr JD dan Sheath RG. 2003. Freswater algae of north america ecology and classification. London: Academic Press.

Wibowo HPE, Purnomo T, dan Ambarwati R. 2009. Water quality of the bengawan solo river in bojonegoro based on plankton diversity index. Lentera Bio, 3(3): 209215.

Winahyu, D.A., Yulistia, A., Elly, L., Rustiati., Jani, M \& Andi, S. 2013. Studi Pendahuluan Mengenai Keanekaragaman Mikroalga di Pusat Konservasi Gajah, Taman Nasional Way Kambas. Prosiding Semirata FMIPA Universitas Lampung.

Yudasmara GA. 2015. Analisis keanekaragaman dan kemelimpahan relatif algae mikroskopis di berbagai ekosistem pada kawasan intertidal pulau menjangan Bali Barat. Jurnal Sains Dan Teknologi, 4(1): 503-515.

Yuliana Y, Adiwilaga EM., Harris E, dan Pratiwi NTM. 2012. Hubungan antara kelimpahan fitoplankton dengan parameter fisik-kimiawi perairan di teluk Jakarta. Jurnal Akutaika 3(2):169-179. 